\title{
Adopting Agile Methods in the Public Sector: A Systematic Literature Review
}

\author{
Isaque Vacari \\ Embrapa Informática Agropecuária \\ Empresa Brasileira de Pesquisa Agropecuária, Embrapa \\ Campinas/SP, Brazil \\ isaque.vacari@embrapa.br
}

\begin{abstract}
Agile software development (ASD) has become an important research topic. However, despite the increase in the number of studies in this area in the last few years, there is a lack of structured information about its adoption in the public sector. Since the public sector is the part of the economy concerned with providing various government services, the goal of this study is to report from a systematic literature review and provide information that may enhance the understanding of the implications of adopting ASD within public companies. As the main results, we found that ASD could indeed be adopted in the public sector. The analysis suggests that a good alternative is to start the adoption of ASD with people willing to change - strongly supported by senior management - working on important pilotprojects. Second, we found that job satisfaction is greater when adopting agile methods within public companies. Finally, we also found some barriers that are difficult to overcome, including the ingrained use of plan-drive methods, as well as big bang deliveries and lack of experience in ASD.
\end{abstract}

Keywords: agile methodologies; software development; software engineering; public organizations; government.

\section{INTRODUCTION}

The public sector is the part of the economy concerned with providing various government services. With the development and evolution of technology in the past few years, public organizations began to gradually incorporate software products in their development processes. Thus, the incentive to adopt new and better approaches to Software Engineering (SE) has become something essential for the future of software projects in government. In the context of SE, the government always attempted to enforce software standards for the development of its systems, based on plan-driven methods with big bang deliveries. For example, the United States Department of Defense attempted to enforce "US Military Software Development Standards" from the 1970s to 1990s [1]. Also, the United Kingdom (UK) Government decided to adopt "Structured Systems Analysis and Design Method" from the 1980s to mid-2000s [2]. The benefits are that it contributed to spreading the use of valuable techniques. On the other hand, software standards based on plan-driven methods are unlikely to cope well with uncertainty, changing requirements, user communication and staff development [2].

A good solution to these problems was formalized in February of 2001 with the agile methods. Since then the government has gradually waived its ways of working and has adopted agile software development [3]. Although ASD has

\author{
Rafael Prikladnicki \\ Faculdade de Informática \\ Pontifícia Universidade Católica do Rio Grande do Sul \\ Porto Alegre/RS, Brazil \\ rafaelp@pucrs.br
}

become an important research topic and the number of studies in this area has increased in the last few years, there is a lack of structured information about its adoption in the public sector. For this reason, the goal of this study is to report from a systematic literature review about the adoption of agile methods in the public sector and provide empirical evidence about its current situation, challenges, and opportunities.

Public organizations have been adopting agile methods in order to improve the results of their IT projects [7][8][9]. This is motivated by the benefits that agile methods can bring to organizations, including the ability to manage changing priorities, better alignment between IT and business objectives, enhanced software quality and increased customers / users / stakeholders satisfaction with the software product [10].

However, the adoption of agile methods in the public sector has some challenges. Agile methods are incompatible with hierarchical and bureaucratic structures, typical of government [11]. Many public organizations, especially large ones, have spent years changing their culture so that the processes were defined and followed, it is difficult to switch to a working model in which the processes are informal and defined by the development team [3]. Even so, agile methods can bring better results for the public sector, than those that would be possible to achieve with plan-drive methods big bang deliveries [3].

This paper organized as follows: in Section II, we present the method. In Section III, we set out the results, while in Section IV we discuss the findings. In Section V, the limitations of the study are discussed. Finally, in Section VI the conclusions and future work are addressed.

\section{RESEARCH METHODOLOGY}

The research methodology used is a systematic literature review. The main purpose was to find evidence regarding the adoption of agile methods in the public sector. Our review protocol was based on the recommendations provided by Kitchenham [4], and the research question that guided the systematic review was:

\section{What is known about the adoption of agile methods in the public sector?}

The search included digital libraries available and papers published in journals, conference and workshop proceedings. We searched seven digital libraries and one-conference proceedings, the following: ACM Digital Library, Bielefeld 
Academic Search Engine (BASE), ScienceDirect, Engineering Village, IEEEXplore, Scopus, SpringerLink, Web of Knowledge and Wiley. In extra, we hand-searched Portuguese studies for research papers: Bases de Dados da Pesquisa Agropecuária (BDPA), Biblioteca Digital Brasileira de Computação, Workshop Brasileiro de Métodos Ágeis (WBMA).

The keywords were defined based on two main categories of terms: those related to "Public Sector", and those related to "Software Development". Table I outlines the keywords.

TABLE I. KEYWORDS USED IN THE REVIEW PROCESS.

\begin{tabular}{|c|c|c|}
\hline Reference & Category & Keywords \\
\hline A & Public Sector & $\begin{array}{l}\text { Government (1) } \\
\text { Public sector (2) } \\
\text { Public administration (3) } \\
\text { Public organization (4) }\end{array}$ \\
\hline B & $\begin{array}{l}\text { Software } \\
\text { Development }\end{array}$ & $\begin{array}{l}\text { Software development life cycle (5) } \\
\text { Software development methodology (6) } \\
\text { Software development process (7) } \\
\text { Software development projects (8) } \\
\text { Software process (9) } \\
\text { Unified process (10) } \\
\text { Rational unified process (11) } \\
\text { RUP (12) } \\
\text { Microsoft solutions framework (13) } \\
\text { Agile methodologies (14) } \\
\text { Agile methods (15) } \\
\text { Agile principles (16) } \\
\text { Agile process (17) } \\
\text { Agile software development (18) } \\
\text { Extreme programming (19) } \\
\text { Lean software development (20) }\end{array}$ \\
\hline
\end{tabular}

The search was a combination of A and B. Category B has more keywords and reflects the fact that there are many variations of the same term. We defined the search string as:

(1 OR 2 OR 3 OR 4) AND (5 OR 6 OR 7 OR 8 OR ... 20)

Figure 1 shows the systematic review process and the number of papers identified at each stage.

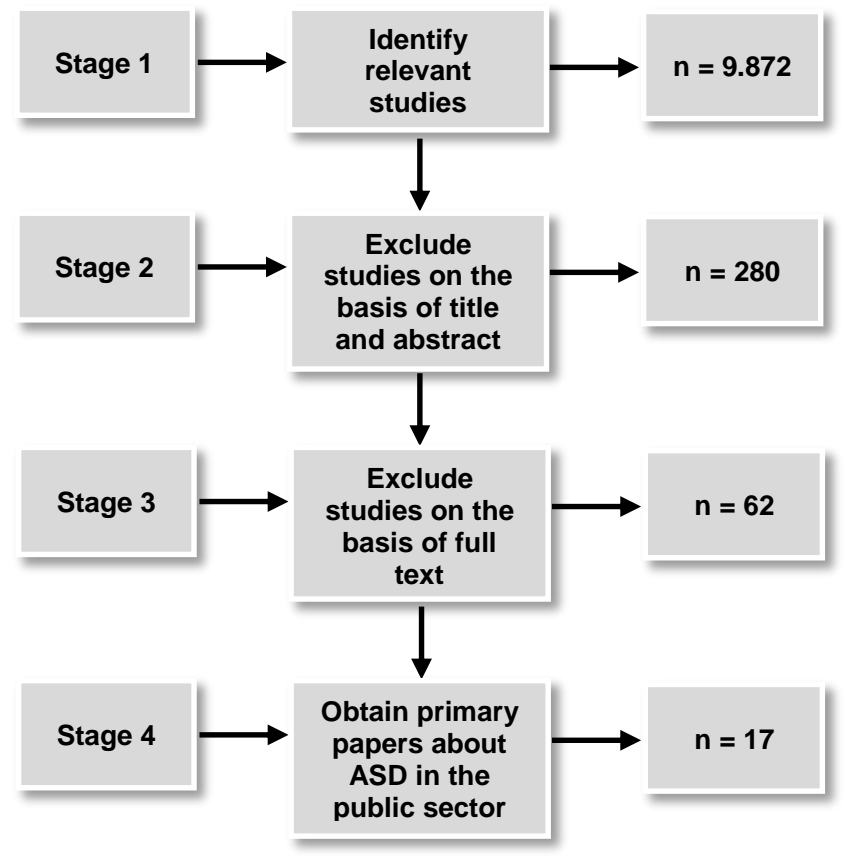

Figure 1. Stages of the study selection process.
We searched for government experience reports and empirical papers. This search strategy resulted in a total of 9.872 citations. As we can see, the lack of standard terminology in "Public Sector" and "Software Development" resulted in a large number of papers to start with, but only a few were selected, confirming the high sensitivity and low precision of our search.

To include a paper in the analysis, the paper must have been available online, must have been written in English or Portuguese, and must have described the aspects of the adoption of agile methods in the public sector. The papers were classified following a three-step approach. First, based on the reading of the papers' titles and abstracts, the papers were classified into three categories:

- [Inc], indicating the papers collected and possibly related to software development in the public sector.

- $\quad[$ Exc], indicating the papers collected but not related to software development in the public sector.

- $\quad[$ Dup], indicating the papers collected but repeated with other studies.

All the papers in category [Exc] or [Dup] were excluded, while the papers in category [Inc] were analyzed more carefully based on the reading of the full text (introduction, conclusion, and specific parts related to the main contribution). Then, a subset of papers in [Inc] related to software development in the public sector was selected for the next step. Finally, a new subset of papers in [Inc] was selected, keeping only those addressing regarding agile software developments in the public sector.

After this process, the papers were classified according to three general categories of information:

- General information: digital library, title, authors, source (e.g. journal or conference proceedings) type of source (i.e. journal, conference, workshop, technical report), and category ([Inc] or [Exc] or [Dup]).

- Research-related information: type of paper (i.e. theoretical, industrial experience report, or empirical study), research empirical strategy (i.e. case study, survey, experiment, ethnography, action research, combination), data collection methods (i.e. interview, observation, questionnaire, document inspection, or multiple data collection methods), type of data analysis (i.e. qualitative, quantitative or both), and data analysis method (i.e. statistics, grounded theory, content analysis). For papers reporting empirical work, the type of study was classified according to the proposal in Dias Neto et al. [5]. Research strategy, data collection, type and method of data analysis were classified according to the terminology used by Oates [6].

- Content-related information: aspects of the adoption of agile methods (i.e. reasons, benefits, problems and challenges, recommendations), project features (i.e. team size, agile method, agile experience, project duration, domain, customers, contractors), attributes, and general comments. 
TABLE II. PAPERS SELECTED FOR ANALYSIS.

\begin{tabular}{|c|c|c|c|c|}
\hline Study & $D L$ & Title & Authors & Year \\
\hline [P01] & Scopus & $\begin{array}{l}\text { A case study: Introducing eXtreme programming in a US government system } \\
\text { development project }\end{array}$ & A. Fruhling, P. McDonald, and C. Dunbar & 2008 \\
\hline [P02] & Scopus & Staying agile in government software projects & B. Upender & 2005 \\
\hline [P04] & Scopus & The FBI gets agile & $\begin{array}{l}\text { C. Fulgham; J. Johnson; M. Crandall; L. } \\
\text { Jackson; N. Burrows }\end{array}$ & 2011 \\
\hline [P06] & IEEE & $\begin{array}{l}\text { Making agile development work in a government contracting environment- } \\
\text { measuring velocity with earned value }\end{array}$ & G.B. Alleman, and M. Henderson & 2003 \\
\hline [P07] & Scopus & Agile development in a bureaucratic arena - A case study experience & H. Berger & 2007 \\
\hline [P08] & Scopus & An industrial case study for Scrum adoption & H. Hajjdiab, A. S. Taleb, and J. Ali & 2012 \\
\hline [P09] & Scopus & Army simulation program balances agile and traditional methods with success & J. Surdu, and D.J. Parsons & 2006 \\
\hline [P12] & Scopus & Lessons learned using agile methods on large defense contracts & P. E. McMahon & 2006 \\
\hline [P13] & IEEE & Evolving to a "lighter" software process: a case study & R. J. Moore & 2001 \\
\hline [P14] & Springer & Is Agile the Answer? The Case of UK Universal Credit & R. Michaelson & 2013 \\
\hline [P15] & Scopus & Agile software development under university-government cooperation & S. Kaneda & 2006 \\
\hline [P16] & Scopus & Exploring XP for scientific research & W. A. Wood, and W. L. Kleb & 2003 \\
\hline [P17] & Scopus & Agile metrics at the Israeli Air Force & $\begin{array}{l}\text { Y. Dubinsky, D. Talby, O. Hazzan, and A. } \\
\text { Keren }\end{array}$ & 2005 \\
\hline
\end{tabular}

TABLE III. OVERVIEW OF THE STUDIES.

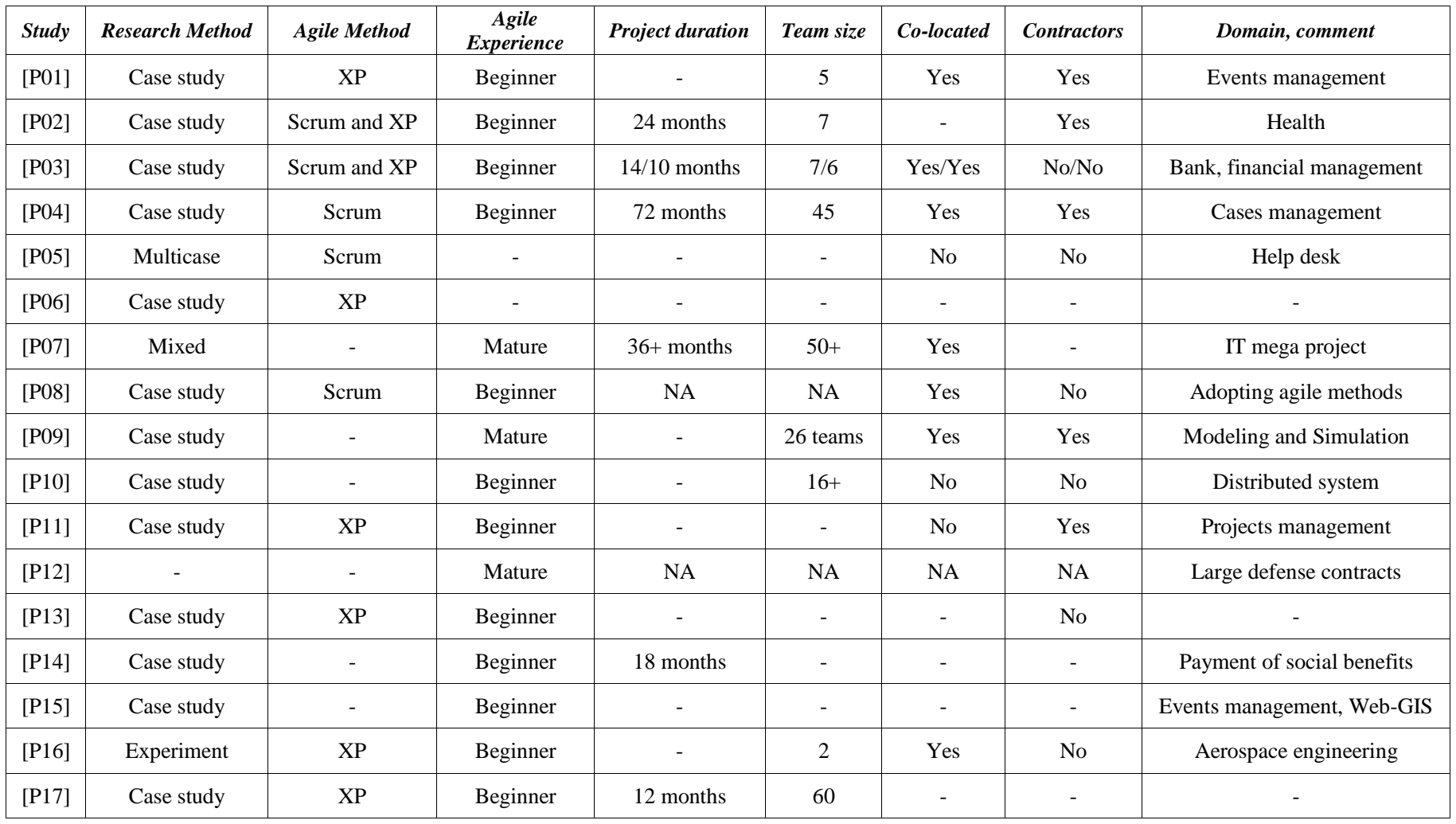




\section{RESULTS}

The systematic literature review was conducted from August 2013 to March 2014 and we identified 17 primary studies on agile software development in the public sector (see Table II). Key data, along with a description of the domain in which each study was conducted, is presented in Table III.

We categorized the studies into three main groups: (1) reason and benefits obtained from adopting agile methods in the public sector, (2) problems and challenges faced from adopting agile methods in the public sector, and (3) lessons learned obtained from adopting agile methods in the public sector.

\section{A. Reasons and benefits benefits obtained from adopting agile methods in the public sector}

One of the biggest reasons for the adoption of agile methods is the benefits that they can bring to the government, which are a response to a history of failure of IT projects in public sector. Thirteen studies described some benefits obtained from adopting agile methods in the public sector. Table IV presents these studies.

TABLE IV. BENEFITS OBTAINED FROM ADOPTIONG AGILE METHODS IN THE PUBLIC SECTOR.

\begin{tabular}{|l|l|}
\hline Factor & Study \\
\hline $\begin{array}{l}\text { Deliver value to customers/stakeholders } \\
\text { earlier }\end{array}$ & {$[\mathrm{P} 02][\mathrm{P} 09][\mathrm{P} 12][\mathrm{P} 13]$} \\
\hline Better collaboration between IT and business & $\begin{array}{l}{[\mathrm{P} 01][\mathrm{P} 02][\mathrm{P} 04][\mathrm{P} 05]} \\
{[\mathrm{P} 07][\mathrm{P} 09][\mathrm{P} 10][\mathrm{P} 17]}\end{array}$ \\
\hline Improved customer/stakeholder satisfaction & $\begin{array}{l}{[\mathrm{P} 01][\mathrm{P} 02][\mathrm{P} 03][\mathrm{P} 04]} \\
{[\mathrm{P} 10]}\end{array}$ \\
\hline $\begin{array}{l}\text { Improved team morale and reduced } \\
\text { dependence on contractors }\end{array}$ & {$[\mathrm{P} 03][\mathrm{P} 11][\mathrm{P} 17]$} \\
\hline Improved communication & {$[\mathrm{P01}][\mathrm{P02}][\mathrm{P04}][\mathrm{P} 09]$} \\
\hline Improvement in learning new technologies & {$[\mathrm{P} 03]$} \\
\hline Improved product quality & {$[\mathrm{P} 16]$} \\
\hline Improved project visibility & {$[\mathrm{P} 02][\mathrm{P} 12][\mathrm{P} 17]$} \\
\hline Increased productivity & {$[\mathrm{P} 03][\mathrm{P} 16]$} \\
\hline Reduced cost & {$[\mathrm{P} 07]$} \\
\hline Improved manage changing priorities & {$[\mathrm{P} 05][\mathrm{P} 17]$} \\
\hline
\end{tabular}

Based on Table IV, we can observe that benefits were reported in the following areas: customer/stakeholder collaboration and alignment between IT and business object. Some studies have found that job satisfaction is greater, developers are more satisfied with their job and that customers are more satisfied with the product. However, a study did not find any benefit, and the evidences suggest that not all development environments have evolved with the same pace. For this reason, an organization's inherent culture may not match the development approach adopted, causing project failures [P07].

\section{B. Problems and challenges faced from adopting agile methods in the public sector}

In some cases, the optimistic view of agile methods can be imposed by a practical reality dominated by problems and challenges. Table $\mathrm{V}$ presents some of problems and challenges found.
TABLE V. PROBLEMS AND CHALLENGES FROM ADOPTIONG AGILE METHODS IN THE PUBLIC SECTOR.

\begin{tabular}{|l|l|}
\hline Factor & Study \\
\hline Organizational culture & $\begin{array}{l}{[\mathrm{P} 01][\mathrm{P} 02][\mathrm{P} 03][\mathrm{P} 07][\mathrm{P} 08]} \\
{[\mathrm{P} 14][\mathrm{P} 15][\mathrm{P} 16][\mathrm{P} 17]}\end{array}$ \\
\hline $\begin{array}{l}\text { Lack of knowledge and experience with } \\
\text { agile methods }\end{array}$ & $\begin{array}{l}{[\mathrm{P} 01][\mathrm{P} 02][\mathrm{P} 03][\mathrm{P} 08][\mathrm{P} 11]} \\
{[\mathrm{P} 14][\mathrm{P} 17]}\end{array}$ \\
\hline $\begin{array}{l}\text { Little or no involvement of } \\
\text { customers/stakeholders }\end{array}$ & {$[\mathrm{P} 07]$} \\
\hline $\begin{array}{l}\text { The ingrained use of prescriptive } \\
\text { approaches and big bang deliveries }\end{array}$ & $\begin{array}{l}{[\mathrm{P} 01][\mathrm{P} 03][\mathrm{P} 04][\mathrm{P} 08][\mathrm{P} 15]} \\
{[\mathrm{P} 17]}\end{array}$ \\
\hline $\begin{array}{l}\text { IT mega projects } \\
{[\mathrm{P} 04][\mathrm{P} 14]}\end{array}$ \\
\hline $\begin{array}{l}\text { Traditional procurement and contracts } \\
{[\mathrm{P} 01][\mathrm{P} 03][\mathrm{P} 04]}\end{array}$ \\
\hline $\begin{array}{l}\text { Compliance with standards and } \\
\text { regulations }\end{array}$ & {$[\mathrm{P} 04][\mathrm{P} 06][\mathrm{P} 09][\mathrm{P} 12]$} \\
\hline The lack of senior management support & {$[\mathrm{P} 03][\mathrm{P} 07][\mathrm{P} 08][\mathrm{P} 16][\mathrm{P} 17]$} \\
\hline Delays & {$[\mathrm{P} 01][\mathrm{P} 04][\mathrm{P} 07][\mathrm{P} 08]$} \\
\hline
\end{tabular}

Based on Table $\mathrm{V}$, the organizational culture is a primary factor for the success of any change initiative, including the adoption of a new approach to developing software. Although the culture incorporates many facets, we want to highlight just one specific part, since it presents relevant elements to agile methods in the public sector. This part is "The ingrained use of prescriptive approaches and big bang deliveries". Although various aspects of adaptive development have been advocated and valued by the US and UK Government lately [7] [8], there is still a bias towards prescriptive approaches and big bang deliveries in public sector. The roots of this trend are often associated with traditional procurement and contracts [3]. The US Government has to follow procurement processes that exacerbate the tendency to big projects, prescriptive approaches and big bang deliveries [3]. On the other hand, recently, the UK Government published a new clarification of business case guidance, explaining how government organizations get permission to spend money on agile work, supporting an agile culture in the public sector [9].

Moreover, some studies reported that agile software development practices are easy to understand, but applying them in practice can be difficult.

- Teams did not recognize value in Pair Programming

Studies: [P01] [P11]

- Teams encountered difficulties to write unit tests Studies: [P03]

- Teams did not adopt Test-Driven Development (TDD) because of the lack of real examples

Studies: [P11]

- Teams have not found benefits on acceptance testing for web applications, due to frequent changes

Studies: [P02]

- Teams faced difficulties in convincing customers to deploy partial system in production, even if they add value to business

Studies: [P03] 
- Teams reported difficulties in implementing iterative and incremental development

Studies: [P17]

\section{Lessons learned from adopting agile methods in the public} sector

One of the best ways to increase organizational memory is by conducting a lessons learned session. The storage and dissemination of lessons learned make the organization of workers reflect on experiences and use organizational memory as a starting point for present and future decisions. Some lessons learned are presented in the following dimensions:

1) Team

- $\quad$ Agile methods require knowledge and experience of the team

Studies: [P01]

- Training and coaching contributes to the formation of teams with less experience in agile methods

Studies: [P01] [P02] [P03] [P08] [P09] [P17]

- Agile encourages the formation of small and interdisciplinary teams, which reduces the complexity of communication and the time for decision-making

Studies: [P04]

- $\quad$ Agile can be adopted by geographically distributed software development teams

Studies: [P05]

2) Customer relationship

- Agile requires commitment and preparation, both for customers and developers to achieve their full potential

Studies: [P05] [P11]

- Agile opens the software development process to the customers through a direct communication with developers

Studies: [P01] [P04] [P07] [P09] [P10] [P11] [P17]

- $\quad$ Agile requires timely communication, accurate and complete among all members of the development team, customer and end-users

Studies: [P01]

- The best solutions are created when the customer is actively involved in the software development

Studies: [P07]

3) Relationship with business

- Incremental and regular delivery of software are important to demonstrate the emerging solution for customers/stakeholders, which increases trust between all project members

Studies: [P02]

- Progress meetings to communicate project status are tailored for specific audiences

Studies: [P01]
- Agile requires earned value management to maintain compliance with government regulations at all levels

Studies: [P04] [P06] [P09] [P12]

- Agile metrics are essential to make the decisionmaking more efficient and are important to promote project visibility sooner

Studies: [P02] [P12] [P17]

- Agile contracts requires negotiable scope

Studies: [P04]

4) Processes and practices

- $\quad$ Agile practices are simple to understand, however, to internalize them and follow them is strictly difficult

Studies: [P02] [P03] [P08] [P17]

- Agile achieves better results when government experts and developers work together with contractors in all phases of software development, in the same physical location and near customers

Studies: [P04] [P09]

- Pair Programming can be used in specific tasks of software development

Studies: [P02] [P16]

- To support Pair Programming the layout of the rooms of the developers needs to be changed

Studies: [P16]

- Agile requires more written tests by developers, which are executed automatically

Studies: [P03] [P04] [P09] [P10] [P11] [P13] [P16] [P17]

- Agile does not require less written documents and can be combined with prescriptive approaches

Studies: [P02] [P09]

- User experience aspects need to be considered from the earliest iterations

Studies: [P01]

5) Software tools

- Collaborative tools facilitate the adoption of agile methods

Studies: [P03] [P09] [P11] [P13]

\section{DISCUSSION}

In this section we discuss our findings as follows.

\section{A. Agile methods can be adopted in the public sector}

We found that agile methods could be adopted in the public sector. In some studies, the results were better than those possible to achieve with prescriptive approaches. This is partly because customers/stakeholders are no longer just at the fringes of software development, but actively shaped and guided the evolution of the end software product or service. Secondly, there is a learning element inserted into each delivery cycle and a job satisfaction [P01][P02][P03][P04][P10][P11][P16][P17]. 


\section{B. Adopting agile methods in the public sector can be even more challenging}

The analysis suggests that agile software development in the public sector can be more challenging because people with little experience need to direct projects towards success with positive results in the short term, and sometimes they do not have the support organization necessary, and still depend tightly on external coaches [P08].

\section{Adopting agile methods in the public sector can be slower and complex}

The studies that address the adoption of agile methods suggests that a good alternative is to start the adoption of agile software development with people willing to change - strongly supported by senior management - working on important pilotprojects. After, the change will depend on their interaction with other teams, in order to reach the vast majority of the organization, which can be slower and complex [P01][P03][P11][P16]. One study showed that implementation of agile methods across the organization is recommended only when the negative results remain constant in time [P04]. In general, big bang adoption approach is not recommended, being more prone to failure [P08].

\section{There is a need for more studies related to agile procurement}

In government, the emphasis is on risk management through rigorous procurement processes, which generally includes a prescriptive fixed-price and fixed-requirement contract between client (government) and supplier (software industry) [3]. This approach is in disagreement with agile principles. As a result, those using agile development in the public sector are opting for resource augmentation (use of a supplier's staff on a time and materials basis) to run agile projects internally [P04] [P09]. This creates an opportunity for researchers to explore and understand the degree to which this approach is useful or appropriate to agile procurement context.

\section{E. Aspects of the adoption of agile methods in the public sector should be empirically evaluated}

Agile methods have not been sufficiently tested and exploited in the public sector. In addition, there is a restricted set of scientific evidence to extract conclusive results. However, there are promising results from adopting agile methods in public sector. Therefore, there is an opportunity for SE researchers to understand how these methodologies are adopted in practice and which effects they generate, including their advantages and disadvantages.

\section{LIMITATIONS}

Systematic literature review is a useful method. However, as any other method, there are some limitations. We address three of them. First, we see that the primary studies selected in our systematic review present significantly more evidence on success than failure cases. This may have limited or influenced the results.
Second, the full text of the articles was obtained through the libraries at the Brazilian Agricultural Research Corporation (Embrapa), Pontifícia Universidade Católica do Rio Grande do Sul (PUCRS) and University of Campinas (Unicamp). For this reason, some studies that could be related with the subject were not analyzed because they were not accessible.

Finally, the immediate definition of search strategy makes knowledge as something well defined and explicit. However, new knowledge was discovered while performing a systematic review, which could have resulted in a reformulation of the search strategy, along with a new execution of the whole process with the new discoveries. This means that an initial description accurate of reality makes it difficult to apply this method successfully, since the knowledge can also be volatile, tacit and diffuse.

\section{CONCLUSIONS}

In this paper we report from a systematic literature review about adopting agile methods in the public sector. We found that agile methods could be adopted in the public sector. However, not all the implications of adopting agile methods in the public sector are widely known. For this reason, as next steps we plan to interview ASD teams from public organizations, aiming at expanding "what is known about the adoption of agile methods in the public sector", proposing a set of recommendations for adopting agile methods in this context.

\section{REFERENCES}

[1] C. McDonald, "From art form to engineering discipline? A history of US military software development standards, 1974-1998," IEEE Annals of the History of Computing, vol. 32-4, pp. 32-47, December 2010.

[2] P. Middleton, "Managing information system development in bureaucracies," Information and Software Technology, vol. 41-8, pp. 473482, June 1999.

[3] B. Wernham, Agile project management for government. London: Maitland and Strong, 2012.

[4] B. Kitchenham and S. Charters, "Guidelines for performing systematic literature reviews in software engineering". Technical Report, p. 57. Keele University and Durham University.

[5] A. C. Dias Neto, R. Subramanyan, M. Vieira, G. H. Travassos, Characterization of model-based software testing approaches, Technical Report TR - ES 713/07, COPPE/UFRJ, 2007.

[6] B. J. Oates, Researching information systems and computing. CA: Sage Publications, 2006.

[7] US GAO, "Software development: Effective practices and federal challenges in applying agile methods," United States Government Accountability Office, 2012.

[8] UK NAO, “Governance for agile delivery," National Audit Office, 2012.

[9] HM Treasury, "Guidance: Agile digital and IT projects: clarification of business case guidance," HM Treasury.

[10] VERSIONONE, "8th Annual state of agile development survey". VersionOne, 2013.

[11] J. Iivari and N. Iivari, "Organizational culture and the deployment of agile methods: The competing values model view," in: Agile Software Development - Current Research and Future Directions, Springer Berlin Heidelberg, 2010, pp. 203-222. 